International Journal of Engineering \& Technology, $7(3.12)(2018)$ 643-647
International Journal of Engineering \& Technology
SPC
Website: www.sciencepubco.com/index.php/IJET
Research paper

\title{
Application of Ancient Principles of Architecture in Modern Practice
}

\author{
Marshal DG ${ }^{1}$, Prakash $A^{2}$, Venkatasubramanian $C^{3}$, Muthu $D^{4}$, Madhan Vignesh $\mathbf{M}^{5}$ \\ School of Civil Engineering, SASTRA Deemed University, Thanjavur, Tamil Nadu, India \\ *Corresponding Author Email: ${ }^{\text {}}$ marshaldg97@gmail.com
}

\begin{abstract}
Before the advent of reinforced cement concrete and steel structures in the $20^{\text {th }}$ century, structures like Arches, domes and vaults were being widely used worldwide. Arches were mainly used in span openings replacing beams. This was done based on the erstwhile cultural aesthetics and technical development in the prevailing construction methodologies. Nowadays, about 35 to 40 percentage of the total construction cost is being consumed by steel and concrete and therefore constructing a building without steel and concrete contributes to reduction in cost. Vaults and arches do not require concrete and steel but use only bricks and hence environment friendly. This paper deals with the design and construction procedure for structural members including the vault and buttress wall. It also highlights the reduction in cost when adopting vault method over conventional methods, in a residential building. The Vault prototype has been made with the studied design and concepts. The idea is to introduce this technique as a cost reduction approach and to preserve this ancient construction technique. Also, this method will be economical for construction of low cost houses up to two storeys.
\end{abstract}

\section{Introduction}

Vault is an ancient construction technique used largely in ancient temples whose use is greatly reduced after the introduction of steel and concrete. In a structure, steel and concrete occupies 35 to 40 percentage of the total cost, therefore construction a building without steel and concrete would reduce the cost of construction. People are unaware of the benefits of this construction technique. Vault structures are environment friendly since they use clay bricks. The reduction in cost when adopting vault method is arrived through estimation. The complete procedure for construction of the structural members has been studied and a prototype was made.

\section{Literature Review}

1 Vaulted systems for low-cost construction in Africa. Philippe Block, et al. ATDF JOURNAL, Volume 7, Issue 1/2 2010 - This paper deals about using vaulted structural systems to provide sustainable and low-cost construction for Africa, based on experiences both in and practice.

2 Traditional vault construction without formwork: Masonry pattern and vault shape in historical technical literature and in experimental studies David Wenland. International Journal of
Architectural heritage, Volume 1, Issue 4,2007. This article aims in a better understanding of the traditional technique and to provide the base of the design process. Beyond that, an accurate surface model for vaults is proposed to be helpful for the numerical modeling of their structural behavior.

\section{Methodology}

The design and construction process of the structural members such as vault, buttress wall for a residential building is studied and the detailed estimate is worked out to find the cost reduction.

\section{Design Procedure}

\section{Floor Plan}

A plan for 2 BHK house with dimensions 22.25 x $42.25 \mathrm{ft}$. have been prepared. The house has been designed for ground floor only and it is divided into two segments so that it has two vaults. The thickness of the wall adopted is $230 \mathrm{~mm}$ and the wall height is 2.1 $\mathrm{m}$. Vault structures have buttress walls instead of columns. The total plinth area including verandah is 940 sq.ft. (refer FIG.4.1) 


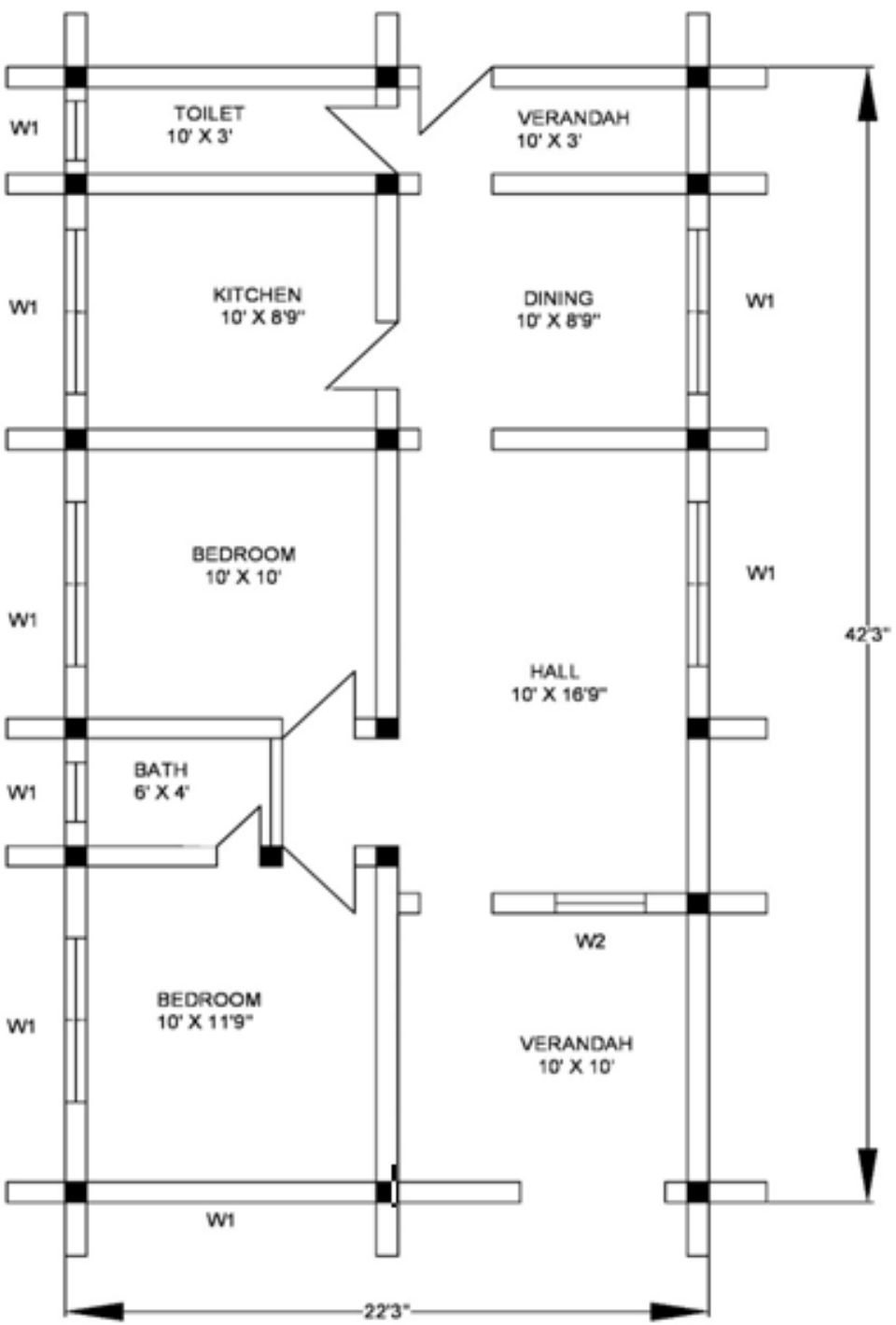

Fig. 1: Floor plan for a two-bedroom house

\section{Vault Design}

Vault is a three-dimensional configuration of arch. The span of room is $3 \mathrm{~m}$. Since the span is very less, semi-circular vault has been adopted. The semicircular vault transfers only the vertical forces and not the lateral forces. The thickness of the vault is proportional to its span.

Design Parameters:

Rise in the center of vault $=\mathrm{span} / 2$

$$
=1.5 \mathrm{~m}
$$

Thickness of the vault $\quad=$ span/12

$$
=250 \mathrm{~mm}
$$

Therefore, the total height of the room becomes $3.6 \mathrm{~m}$ at the center. Lintels above the doors and windows are replaced with semicircular arches. The skewback is made up of chiseled bricks, because the compressive strength of brick is more than that of cement. The skewback is also provided where the two vaults meet.

\section{Construction Procedure}

\section{Sub Structure}

The foundation consists of alternate layers of stone and brick masonry for a depth of $0.75 \mathrm{~m}$. Sand filling for $150 \mathrm{~mm}$ has to be done. Over that a layer of stone block with the thickness of 150 $\mathrm{mm}$ is placed and it is an alternate for conventional PCC. Above that a $450 \mathrm{~mm}$ thick layer of random rubble masonry is to be laid which forms the major part of foundation, then brick masonry for $300 \mathrm{~mm}$ height is constructed following this a stone block of 100 $\mathrm{mm}$ thickness is used as the plinth beam as an alternative for conventional RCC beams.

\section{Super Structure}

The wall is designed for a thickness of $230 \mathrm{~mm}$ and has to be constructed for a height of $2.1 \mathrm{~m}$ using brick masonry. The Vault is raised over the wall structure. Thus, making the roof dome shaped.

\section{Buttress Wall}

Buttress wall is provided to support the brick wall as it counteracts the forces and moments created due to the dead and live loads from the vault. These are not mandatory at the front and back side of the building but at the sides they play a major role by supporting the main wall.

The foundation, thickness and height of the buttress wall is same as that of the main wall. The length of the buttress wall at top and bottom is $230 \mathrm{~mm}$ and $600 \mathrm{~mm}$ respectively.

\section{Vault}

The formwork for the construction of vault consists of wooden or steel planks which are supported by shoring. Over this, bricks along with mud mortar is placed by threading technique to obtain the curvature. 
Once the formwork is completed, bricks are laid simultaneously from both the sides with the help of thread, such that the center of the thread should be in the center of the brick that is being laid. To maintain the radius the cement mortar on the outer edge should be greater when compared to the inner edge.

The skewback in the place where the two vaults meet should be formed with chiseled bricks. Care should be taken that the skewback has more bricks than cement mortar. Once the vault is finished, the formwork can be removed within a week and a proper water draining arrangements should be made to prevent infiltration of rain water into the vault.[1]

\section{Cost Comparison}

The cost reduction achieved is arrived by comparing the construction of a two-bedroom house by conventional and vault methods.
- This method involves the usage of steel and concrete.

- The foundation involves sand filling, P.C.C and R.C.C.

- The flooring is again P.C.C.

- Plastering is necessary for the roof and for both sides of the walls.

- White washing is necessary.

\section{Vault Technique}

- This method does not need steel and concrete.

- The foundation consists of sand filling, stone and brick masonry.

- Brick flooring can be adopted

- Plastering is not mandatory.

These are the regions where the difference in construction methods can be observed and also, this is where the cost reduction can be acquired.

\section{Conventional Technique}

Table 1: Conventional Technique

\begin{tabular}{|c|l|c|c|c|c|c|}
\hline S. No. & Particulars & Quantity & Unit & Rate & per & Amount \\
\hline 1 & Earthwork excavation in foundation & 77.796 & $\mathrm{~m}^{3}$ & 220 & $\mathrm{~m}^{3}$ & 17,115 \\
\hline 2 & Earthwork Refilling & 23.939 & $\mathrm{~m}^{2}$ & 80 & $\mathrm{~m}^{2}$ & 1,915 \\
\hline 3 & Sand filling in foundation & 10.26 & $\mathrm{~m}^{3}$ & 2824 & $\mathrm{~m}^{3}$ & 28,974 \\
\hline 4 & Cement concrete 1:1.5:3 in foundation & 1.647 & $\mathrm{~m}^{3}$ & 5400 & $\mathrm{~m}^{3}$ & 8,894 \\
\hline 5 & R.C.C work 1:1.5:3 & 30.47 & $\mathrm{~m}^{3}$ & 7000 & $\mathrm{~m}^{3}$ & 213,290 \\
\hline 6 & Mild steel reinforcements & 2124.8 & $\mathrm{~kg}$ & 65 & $\mathrm{~kg}$ & 138,112 \\
\hline 7 & First class B.W in CM 1:6 & 42.56 & $\mathrm{~m}^{3}$ & 5400 & $\mathrm{~m}^{3}$ & 229,824 \\
\hline 8 & Half brick masonry & 18.178 & $\mathrm{~m}^{3}$ & 800 & $\mathrm{~m}^{3}$ & 14,542 \\
\hline 9 & P.C.C. flooring & 9.274 & $\mathrm{~m}^{3}$ & 4200 & $\mathrm{~m}^{3}$ & 38,951 \\
\hline 10 & Grano finish on the top & 61.83 & $\mathrm{~m}^{2}$ & 600 & $\mathrm{~m}^{2}$ & 37,098 \\
\hline 11 & Teakwood (Frame) & 2.4 & $\mathrm{~m}^{3}$ & $1,20,775$ & $\mathrm{~m}^{3}$ & 289,860 \\
\hline 12 & Teakwood (Shutter) & 1.5 & $\mathrm{~m}^{3}$ & $1,20,775$ & $\mathrm{~m}^{3}$ & 181,163 \\
\hline 13 & Plastering & 486.5 & $\mathrm{~m}^{2}$ & 400 & $\mathrm{~m}^{2}$ & 194,600 \\
\hline 14 & White washing & 486.5 & $\mathrm{~m}^{2}$ & 20 & $\mathrm{~m}^{2}$ & 103,760 \\
\hline 15 & Color washing & 412 & $\mathrm{~m}^{2}$ & 30 & $\mathrm{~m}^{2}$ & 133,020 \\
\hline & Total & & & & & $1,631,118$ \\
\hline & Add 2\% for sump & & & & 32,622 \\
\hline & Add 2\% for septic tank & & & & & 32,622 \\
\hline & Add 3\% for contingencies & & & & 3,991 \\
\hline & Add 2\% for work charge establishment & & & & \\
\hline & Add 7\% electrical works & & & & \\
\hline & Add 10\% plumbing & & & & \\
\hline & Total & & & & 13,660 \\
\hline
\end{tabular}

Table 2: Vault Technique

\begin{tabular}{|c|c|c|c|c|c|c|}
\hline S.No. & Particulars & Quantity & Unit & Rate & per & Amount \\
\hline 1 & Earthwork excavation in foundation & 27.718 & $\mathrm{~m}^{3}$ & 220 & $\mathrm{~m}^{3}$ & 6098 \\
\hline 2 & Earthwork refilling & 23.939 & $\mathrm{~m}^{2}$ & 80 & $\mathrm{~m}^{2}$ & 1915 \\
\hline 3 & Sand filling in foundation & 4.732 & $\mathrm{~m}^{3}$ & 2824 & $\mathrm{~m}^{3}$ & 13363 \\
\hline 4 & Stone block in foundation & 4.732 & $\mathrm{~m}^{3}$ & 4000 & $\mathrm{~m}^{3}$ & 18928 \\
\hline 5 & Random rubble masonry in foundation & 16.226 & $\mathrm{~m}^{3}$ & 4000 & $\mathrm{~m}^{3}$ & 64904 \\
\hline 6 & Brick masonry above G.L & 8.497 & $\mathrm{~m}^{3}$ & 4850 & $\mathrm{~m}^{3}$ & 41210 \\
\hline 7 & Stone masonry in Plinth & 2.829 & $\mathrm{~m}^{3}$ & 4360 & $\mathrm{~m}^{3}$ & 12334 \\
\hline 8 & Brick Masonry in super structure & 39.589 & $\mathrm{~m}^{3}$ & 5800 & $\mathrm{~m}^{3}$ & 229616 \\
\hline 9 & Brick work in vault & 32.64 & $\mathrm{~m}^{3}$ & 6000 & $\mathrm{~m}^{3}$ & 195840 \\
\hline 10 & Quantity of filling in Vault & 11.24 & $\mathrm{~m}^{3}$ & 300 & $\mathrm{~m}^{3}$ & 3372 \\
\hline 11 & Centring for Vaults & 202.37 & $\mathrm{~m}^{2}$ & 200 & $\mathrm{~m}^{2}$ & 40474 \\
\hline 12 & Brick flooring & 61.83 & $\mathrm{~m}^{2}$ & 400 & $\mathrm{~m}^{2}$ & 24732 \\
\hline 13 & Grano finish & 61.83 & $\mathrm{~m}^{2}$ & 600 & $\mathrm{~m}^{2}$ & 37098 \\
\hline 14 & Teakwood (Frame) & 2.4 & $\mathrm{~m}^{3}$ & $1,20,775$ & $\mathrm{~m}^{3}$ & 289860 \\
\hline 15 & Teakwood (Shutter) & 1.5 & $\mathrm{~m}^{3}$ & $1,20,775$ & $\mathrm{~m}^{3}$ & 181163 \\
\hline 16 & Plastering (inside) & 363 & $\mathrm{~m}^{2}$ & 400 & $\mathrm{~m}^{2}$ & 145200 \\
\hline 17 & White washing & 363 & $\mathrm{~m}^{2}$ & 20 & $\mathrm{~m}^{2}$ & 7260 \\
\hline \multirow[t]{9}{*}{18} & Color washing & 293 & $\mathrm{~m}^{2}$ & 30 & $\mathrm{~m}^{2}$ & 8790 \\
\hline & Total & & & & & 1322158 \\
\hline & Add $2 \%$ for sump & & & & & 26443 \\
\hline & Add $2 \%$ for septic tank & & & & & 26443 \\
\hline & Add $3 \%$ for contingencies & & & & & 39665 \\
\hline & Add $2 \%$ for work charge establishment & & & & & 26443 \\
\hline & Add 7\% electrical works & & & & & 92551 \\
\hline & Add $10 \%$ plumbing & & & & & 132216 \\
\hline & Total & & & & & 1665920 \\
\hline
\end{tabular}




\section{Cost Reduction}

The total cost using conventional technique $=18,60,000$ (approx.) The total cost using vault technique $\quad=16,66,000$ (approx.) Cost reduction $\quad=1,94,000$. Percentage $=10.4 \%$

Therefore, a cost reduction of $10.4 \%$ is achieved using vault technique and it can be used for low cost construction.[4]

\section{Prototype Construction}

To understand the construction process of the vault clearly a prototype is built. The main motive is to show the feasibility of vault structures.

\section{Base Making}

A concrete base with reinforcement of $8 \mathrm{~mm}$ diameter bars and 6 mm diameter stirrups is made over which the vault will be built. Wooden planks are used as formwork for concreting. The base makes the prototype portable.

\section{Vault Making}

The bricks of dimension $5 \times 3 \times 1$ inch is used for the model. The form work is made with bricks and mud mortar. The radius is maintained with the help of thread and rods. Bricks are placed simultaneously from both the ends. In order to maintain the curvature threading technique is used. The key block is placed finally, which makes the vault a complete structure. The formwork is removed once the vault has been built.[6]

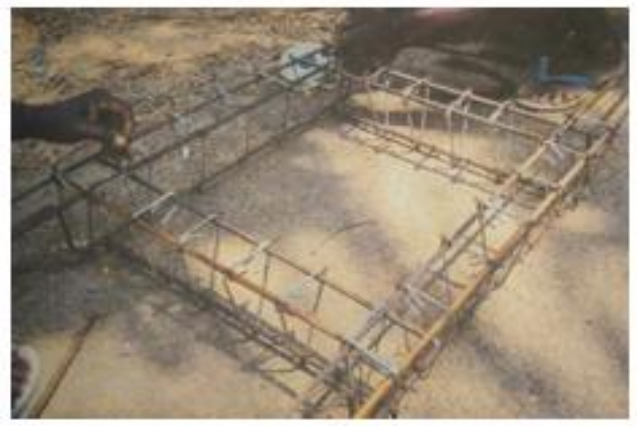

Fig. 2: Reinforcement for base

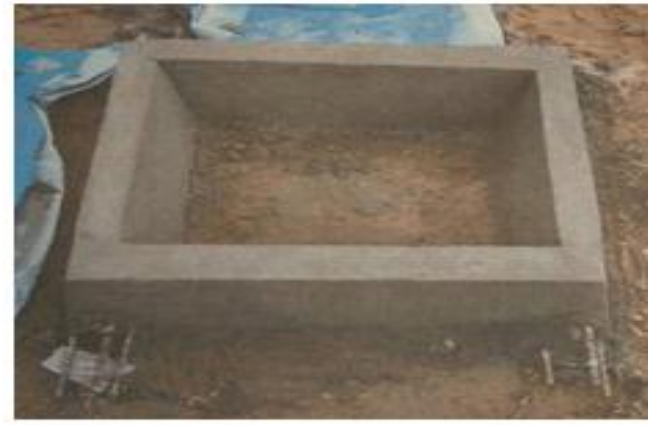

Fig. 3: Base after Concreting

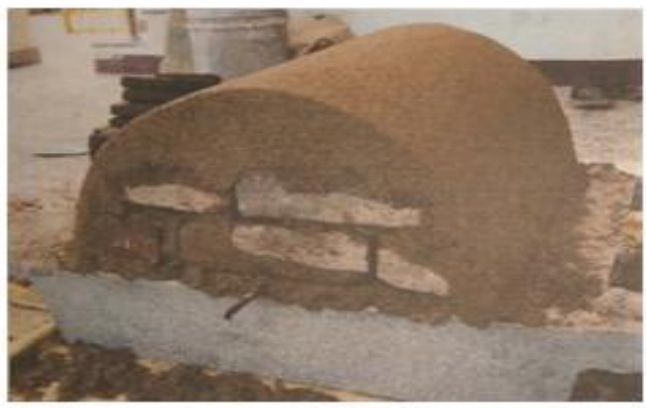

Fig. 4: Formwork

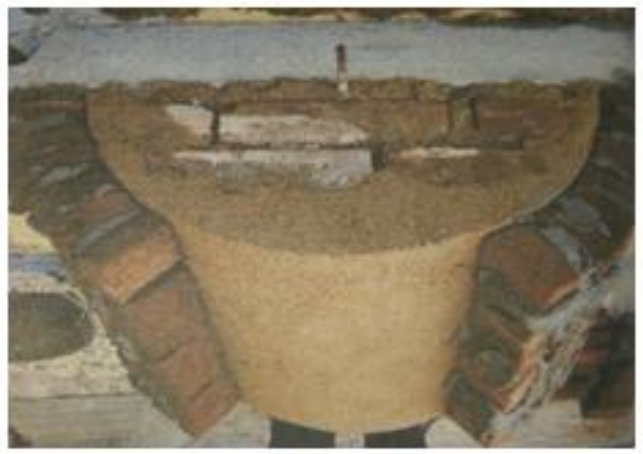

Fig. 5: Bricks Arrangement

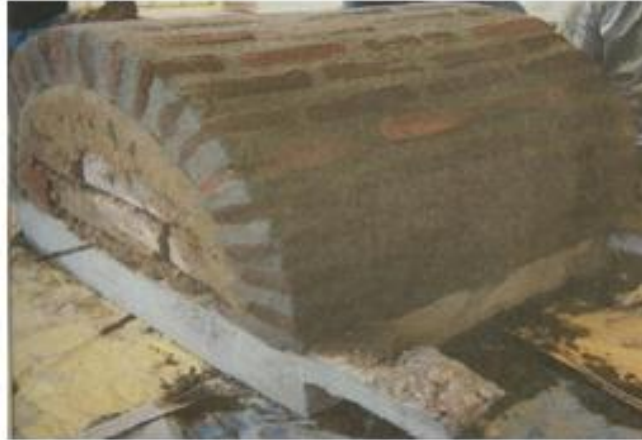

Fig. 6: Finished Vault

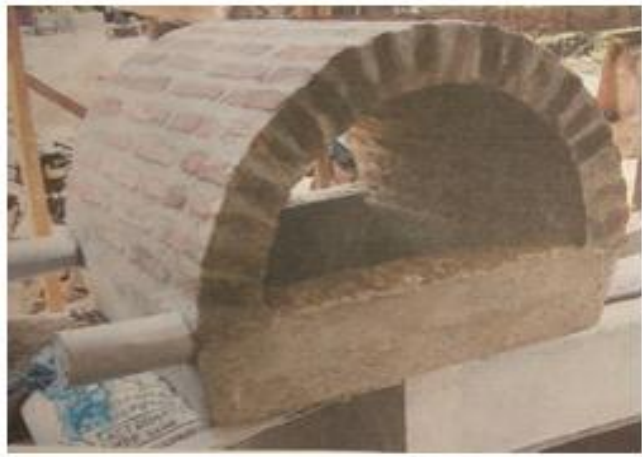

Fig. 7: Vault after removal of formwork

\section{Conclusion}

- Introducing vault in building construction is a cost reduction approach.

- It is environment friendly as the vault construction involves bricks only.

- Vault is limited to $\mathrm{G}+1$ floor only. This is one of the major limitations in vault structures. But introducing concrete in the structure will enable more number of floors in the building.

- Erection and removal of formwork is a difficult task. The formwork involves mud mortar and bricks other than steel props which takes more time to complete and set. Unlike the removal of steel props, removal of mud mortar takes more time.

- $\quad$ Skilled masons are required for vault construction. Since this is an ancient technique masons are not well versed in arch or vault construction now-a-days.

- $\quad$ Vaults cannot be practiced in urban areas. Ramming of piles in nearby areas may tremble the vault structures. Therefor vault structures are recommended only in rural areas as low-cost housing. 


\section{References}

[1] www.earth-auroville.com,Building with earth, Vaulted Structures.

[2] Philippe Block, Matthew DeJong, Lara Davis, John Ochsendorf, Tile Vaulted Systems for Low-cost Construction in Africa, ATDF Journal, Volume 7, Issue 1/2, (2010).

[3] Traditional Vault Construction Without Formwork: Masonry Pattern and Vault Shape in the Historical Technical Literature and in Experimental Studies, David Wenland, International Journal of Architectural Heritage, Volume 1, Issue 4, (2007). 